\title{
A Depreciated Tool for Combating Terrorism: Tactical Psychology
}

\author{
Vaishnavi Sharma* \\ Independent Researcher in Forensic Science, Private Investigator in Noida, India.
}

\begin{abstract}
Terrorism is evolving rapidly, and with the technological advancements new threats are emerging from the 'World of Terror'. Now, it has become crucial than ever to evaluate and channelise our capabilities to curb terrorism. This article evaluates the basics of human behaviour and how it can be tactically used against terrorism. The author has also addressed an important question often raised among the terrorism research community - 'Who becomes a terrorist?'.
\end{abstract}

Keywords: Human behaviour; Terrorism; Tactical psychology

\section{INTRODUCTION}

The act of terror was first marked, when a Jewish organisation, Sicarii, colluded to supplant Romans who invaded their lands. However, the word 'Terrorism' came into existence during the French Revolution in the late 1700 s and gained popularity during the 1970s with the formation of the Provisional Irish Republican Army (PIRA). Terrorism is a relative terminology, for some, it is an act against humanity; and for others, it is the only possible explanation for justice. Since many years, the international community and social scientists have struggled dealing with the complex and multifaced aspects of terrorism.

\section{LITERATURE REVIEW}

Literature review suggests that there are broadly two lines of exploration in the field of terrorism, 'Psychology and genetics based' and 'Defence operation based'. It is important to note that, both lines of research will not complement each other to effectively combat terrorism on the ground level. Till date, psychologists and geneticists have provided us with floating observations that have no prognostic efficacy and currently there is no new direction for further research. However, the defence-based operations need definitive and scientifically backed data to evaluate and tackle the threat posed by terrorist organisations. Adding to this conundrum, there is also a concern that many counter-terrorism agencies refrain from sharing ground level data with researchers citing security concerns. This knowledge-based gap has pushed the state of terrorism research into dormancy. Hence, this article is an attempt to find a new empirical approach for countering terrorism

\section{The science of human behaviour}

The human brain is a prodigious creation in the history of this universe, what it can do or achieve has not been studied to its fullest capacity yet. Unlike any other technology, a human brain is not easy to hack and has near to none loopholes. Geneticists are aware of most of the protein-coding and regulatory genes specific to the human brain but still cannot explain the complex relationship between the 'Human Brain' and its unique set of cognitive processes which constitutes the 'Human Mind'. Quite many researches have been done, to find out genetic pre-disposition towards violence and criminal behaviour. Literature review points a positive correlation between a variant of Mono-Amine Oxidase A (MAOA) gene and aggressive behaviour [1], however, there is no data suggesting a link between MAOA gene variant and terrorism. So, the question arises why is it so tedious to find a concrete and reproducible connection between our genes and the way we think? It is mainly because there is a diversity of variants in our environment, acting either as a catalyst or an inhibitor that affects our biological and chemical processes which in turn influence our thinking abilities. The author argues that functioning of our brain is similar to the Asymmetric Cryptographic Systems which are based on mathematical algorithms of public and private key for enhanced security and confidentiality. In an ideal situation, i.e., assuming there is no possibility of 'man-in-the-middle attack", a public key can be distributed freely over a network without compromising the security of an encrypted message, however, the encrypted message can only be decrypted by the receiver who has the private key that was initially paired with that public key. Now let us talk about the human brain, think of it as the public key. Made up of over 100 billion neurons that communicate chemically, through connections

Correspondence to: Vaishnavi Sharma, Independent Researcher in Forensic Science, Alma Mater at Kings College In London, Currently a Private Investigator in Noida, India, Tel: +91-8800621254. E-mail: vaishnavisharma5603@outlook.com

Received: July 12, 2018, Accepted: September 06, 2019, Published: September 13, 2019

Citation: Sharma V (2019) A Depriciated Tool For Combating Terrorism: Tactical Psychology. J Foren Psy. 4:151. doi: 10.35248/2475-319X.19.4.151

Copyright: (C) 2019 Sharma V. This is an open-access article distributed under the terms of the Creative Commons Attribution License, which permits unrestricted use, distribution, and reproduction in any medium, provided the original author and source are credited. 
called synapses. A detailed description of the function and working of each part of the brain has been well documented. But does the knowledge of the structural and functional operations of the brain have solely helped to effectively and efficiently decrypt the person of interest? Experiments have been conducted in the past; trying to profile terrorists using brain scans. However, the scientists at the US Defence Advanced Project Agency analysed numerous physiological and $\mathrm{AMRI}$ data, concluding that the data in hand did not constitute to a biological profile of a terrorist [2]. Therefore, we should focus on the last part of the puzzle, that is, the private key, which is unique to every human. It is the 'Human Mind', a set of distinctive cognitive processes like emotions, memory, intents, thoughts, perception and judgement. These unique cognitive abilities form the basis to understand the 'Mind of Terrorism'.

\section{The mind-power of terrorism}

To logically analyse the given situation, we will not consider any social definition of the word 'terrorism' or a 'terrorist'. We will consider the literal meaning of the word 'terror' concerning our human race, i.e., any group or organisation that stimulates the psychology of terror and fear in the masses irrespective of their motivations. It is crucial to note that, the author has not included any lone-wolf terrorists. The major reason being, that some profiles of lone-wolf terrorists often show signs of social and psychological disorders [3]. Indeed, they aim to spread terror to highlight their message, either social or political, but they do not have longterm plans and usually do get neutralised by security forces in the aftermath of an attack. The key to understanding the 'Mind Power' of terrorism lies in the fact that; its very own existence and flourishment is the outcome of being an organisation. Defined as a hierarchical arrangement of people to accomplish a purpose, any organisation like any business, that has a purpose, will recruit human resources for higher-level posts who have exceptional leading and deliverance rate to avoid downfall and defeat. Their power lies in functioning as one entity; hence, the main problem is not just a couple of terrorists attacking a population, the problem is the certain section of organisation that is providing logistical, intelligence and strategic support. The human power of any terrorist organisation is governed by their personality traits, they are intelligentially capable, manipulative, tactically sophisticated and possess the ability to adapt and evolve when faced with a threat; for example, with the onset of technology and media, many terrorist organisations have moved towards advertising and recruiting through social media. It was found out through a dataset study of ISIS twitter accounts, that there were at least 170k twitter accounts labelled as potential ISIS community twitter accounts just in the year 2015 [4]. Hence, with all the abilities and expertise the terrorist groups have, it is essential to look at the organisation as a whole and not just the ground crew, as the ground crew are a mere reflection of mind-power the leadership possesses.

\section{Tactical psychology}

National and International security forces work on various levels to combat terrorism. To name a few, it includes Human Intelligence (HUMINT), Signal Intelligence (SIGINT), Imagery Intelligence (IMINT) and ground troops' deployment at high-risk countries. But the point is that most of the times they are used for intelligence gathering and protection of masses against any possible calamities. Also, the military-strategic operations to capture or eliminate target terrorist leaders can sometimes lead to mass outrage and return-fire tactics; for example, on 8 July 2016, Burhan Wani, commander of a Pro-Pakistani militant group in the Indian state of Jammu \& Kashmir, Hizbul-Mujahideen was killed by Indian forces. He gained popularity in the region as he made himself relatable to the Kashmiri youths. His death sparked protests across Kashmir, which resulted in the death of around 55 people and injuring 6000 civilians [5]. Hence, to eliminate retaliatory tactics and minimise the outspread of terrorism, there is a need for deploying 'Tactical Psychology'. Among the community, there is a phrase 'Psychological Warfare'. Generally, it is used to modify the opinions and behaviour of the opposition. However, the fact is, all the terrorist organisations are highly united and motivated because of the strong belief in their religious or political agenda. If it would have been easy to deploy 'psychological warfare' to influence and change their perception to favour our establishments, terrorism would have never been a problem.

In the given situation, we need to formulate tactical psychology specific to the organisation with the aim of weakening and distorting the 'Mind-Power' at the organisational level. If you are aware of a British game 'Jenga', a skill-oriented board game, in which players one at a time remove a block from a tower of 54 blocks. Each removed block is placed upon the top of the tower, thereby weakening the base, which results in the falling of the tower. This is what we want to achieve with any terrorist organisation, 'weakening the base so that the organisation falls apart'. In such a case many blocks would have to be removed at once, to achieve a detectable change and failure in any terrorist organisation. Only focusing on the 'Mind' which is the organisational structure would be naïve. Life and action are only possible if the mind has a body. The active cell members form the body of terrorism. Acting on the behalf of the mind, the body performs all functions. The catch here is the process of communication, without which the whole functioning fails. The cells of the organisation arranged either in a hierarchical or networked manner can be fragmented by strategising and manipulating their environment, specifically by deploying technological, psychological, biological and disinformation techniques. The effect on the fragmented cells can then be studied to understand what really goes on in the field of terrorism. The basic operational strategy is to eliminate all the variables that cannot be externally controlled by us, introduce self-made controlled patterns and focus on the constants for a favourable outcome.

\section{Addressing the dogma}

The research to analyse and profile a terrorist has been a renowned phenomenon since the dawn of terrorism. Innumerable research articles have been published, and most of them state and discuss the fundamental issues that have been lurking since long.

The most thought about question which is often thrown upon the behavioural scientists is, "Who becomes a terrorist and how to assess the risk factors associated with it?' A consensus has been reached, that till now none of the psychological or social research has concluded any set of qualities unique to a terrorist or reached a meaningful predictive validity [6]. This might remain constant due to various reasons. Firstly, the concept of terrorism as a product of a mental disorder or psychopathy has been discredited [7]; given this fact, analysis of genotypic markers for the risk assessment will not yield a generalised terrorist profile. Secondly, 
as the author supports the notion that terrorism flourishes due to its organisational capabilities, it would be similar to asking the question that 'Why does any citizen join its respective national Army/Military, Navy or Air Force institution?' to protect one's country, to use one's potential, patriotic reason, a familial business and so on. So how will it be possible and how intelligent is it, to phenotypically characterise a 'human' who wants to join the military and predict a valid risk assessment? The science behind violence and aggression showed by a terrorist has also been considered, but the question arises from the analogy that, if a Military or a Navy officer shoots and kills an enemy of state, or uses enhanced interrogation techniques to defend the nation, will his or her personality be questioned and analysed for being violent or aggressive? Was anyone of them forced to show such behaviour? Is it a useful measure to understand the act of terrorism? Like any intelligence officer or army personnel will deliberately use violence and aggression to fish out information, terrorists might as well use violence for leverage to meet their political and religious agenda. Finally, the influence of media and journalism has been on a rise, many variables and cognitive influences have been on the rise as well, which impact the public's perception for dealing with the problem at hand. It is evident that the hideous terrorist attacks in the past have jolted the community which has resulted in the activation of our innate human survival instinct, and it requires us to think and contemplate all and any solutions at hand. But the question is, are we focusing on the right questions to combat terrorism? The point is, there is nothing meaningful about the phrase 'A Terrorist Profile'. Practically, it is called Human Behaviour profiling, which can only be done if one has enough personal data on the 'Person of Interest', it may or may not be useful for terrorism studies. It will entirely depend on the quality of the input data.

\section{DISCUSSION AND CONCLUSION}

Indeed, terrorism is a complex issue. Various academicians have mainly focused on understanding the 'Act of Terrorism' rather than channelling the existing knowledge to fight terrorism. The author concludes that as every individual is unique; trying to generate a specific biological and psychological profile of terrorists will never lead to a practical solution to combat terrorism.

The author proposes tactical psychology as an interdisciplinary field that takes advantage of the fact that all terrorists work as a part of an organisation. If psychologists and scientists work together along with intelligence officers to manipulate the organisations internal and external environment, it will not only elicit evidencebased response, highlighting their method of operation but will also give an insight into their capabilities to evolve and learn. This will further aid in gathering information about the organisation's resources and connections, in fighting militancy and mapping sleeper cells. As tactical psychology will involve various biological, chemical and interrogational principles to influence a terrorist's environment, this will help bridge the gap between the science and defence research community.

\section{REFERENCES}

1. Sohrabi S. The criminal gene: The link between MAOA and aggression. BMC Proc. 2015;9:49.

2. Genetic Literacy Project: Science not ideology [Internet]. Pennsylvania: Genetic Literacy Project; C2012-2019. What role might genes play in creating terrorists? 2017.

3. McCauley C, Moskalenko S. Toward a profile of lone wolf terrorists: What moves an individual from radical opinion to radical action. Terror Polit Violence. 2013; 26: 69-85.

4. Alfifi M, Kaghazgaran P, Caverlee J, Morstatter F. Measuring the impact of ISIS social media strategy. Paper presented at Misinformation and misbehavior mining on the web. The $11^{\text {th }}$ ACM International Conference on Web Search and Data Mining. 2018; Los Angeles, California, USA.

5. The Indian Express. Srinagar: The Indian Express Ltd. C2019. Doctors stage protest in JK against civilian deaths in Kashmir unrest; 2016.

6. Horgan J. Psychology of terrorism: Introduction to the special issue. APA. 2017; 72:199-204.

7. Crenshaw M. Decisions to use terrorism: Psychological constraints on instrumental reasoning. Int Soc Mov Res. 1992; 4:29-42. 